\title{
Angiotensin-converting enzyme gene insertion/deletion polymorphism is associated with risk of oral precancerous lesion in betel quid chewers
}

\author{
F-M Chung ${ }^{1,2}$, Y-H Yang ${ }^{3,4}$, C-H Chen ${ }^{2}$, C-C Lin ${ }^{2}$ and T-Y Shieh ${ }^{*, 3}$ \\ 'Department of Clinical Research, Pingtung Christian Hospital, Pingtung 900, Taiwan; ' Graduate Institute of Dental Sciences, College of Dental Medicine, \\ Kaohsiung Medical University, Kaohsiung, Taiwan; ${ }^{3}$ Graduate Institute of Oral Health Sciences, College of Dental Medicine, Kaohsiung Medical University, \\ No. 100, Shih-Chuan Ist Road, Kaohsiung 807, Taiwan; ${ }^{4}$ Statistical Analysis Laboratory, Department of Clinical Research, Kaohsiung Medical University \\ Chung-Ho Memorial Hospital, Kaohsiung 807, Taiwan
}

To investigate whether angiotensin-converting enzyme (ACE) gene insertion/deletion (I/D) polymorphism is related to the risk of oral precancerous lesions (OPL) in Taiwanese subjects who chew betel quid, a total of 6 I betel quid chewers having OPL were compared with 61 asymptomatic betel quid chewers matched for betel quid chewing duration and dosage. The frequency of homozygote for ACE D variant is significantly higher in the case subjects than that of the controls ( 44.3 vs $24.6 \% ; P=0.0$ I 08 ). The adjusted odds ratio of the $\mathrm{D}$ homozygous for the risk of $\mathrm{OPL}$ is 8.10 ( $95 \%$ confidence interval $(\mathrm{Cl})=2.04-32.19, P=0.003$ ). In the allelic base analysis, the $D$ allele is also significantly associated with higher risk of OPL. When grouping the study subjects by smoking status, the association between ACE I/D polymorphism and risk of OPL was only observed in nonsmokers. Our results support the theory that genetic factors may contribute to the susceptibility of OPL and suggest that smoking and genetic factors may be differently involved in the development of OPL.

British Journal of Cancer (2005) 93, 602-606. doi: I0.1038/sj.bjc.6602746 www.bjcancer.com

(c) 2005 Cancer Research UK

Keywords: betel quid; angiotensin-converting enzyme; oral precancerous lesions

Both oral submucous fibrosis (OSF) and oral leukoplakia (OL) are chronic potentially malignant lesions of the oral cavity, the former being characterised by a submucosal fibrosis, resulting in marked rigidity and progressive difficulty in opening the mouth, the latter by chronic white mucosal maculae (Cox and Walker, 1996; Aziz, 1997). The most common oral premalignancies appear to be related to the habit of chewing betel quid, tobacco smoking and heavy alcohol consumption (Cox and Walker, 1996; Yang et al, 2001; Lee et al, 2003; Avon, 2004; Sikdar et al, 2004). These are chronic inflammatory and immunologic processes, which are believed to be attributable to the collective effect of genetic predisposing susceptibility in combination with specific environmental factors (Nair et al, 1999; Chiu et al, 2001, 2002; Kao et al, 2002; Liu et al, 2004; Shin et al, 2004; Sikdar et al, 2004; Tsai et al, 2004).

Angiotensin-converting enzyme (ACE) is expressed in a wide range of tissues (Smallridge et al, 1986; Noveral et al, 1987; Petrov et $a l, 2000)$ and converts angiotensin I to the potent vasoconstrictor angiotensin II (Ang II). The latter may be involved in the fibrotic process because it acts as a proinflammatory cytokine, participating in various steps of the inflammatory response (Mezzano et al, 2001). Studies have also demonstrated that ACE insertion/deletion (I/D) polymorphism is associated with fibrotic and atherosclerotic cardiovascular disease (Mezzano et al, 2001;

*Correspondence: Dr T-Y Shieh; E-mail: tiyush@kmu.edu.tw Received 22 April 2005; revised 8 July 2005; accepted 13 July 2005
Morrison et al, 2001; Arkwright et al, 2003; Luther et al, 2003). Thus, ACE might be a candidate gene for OSF and OL. We therefore investigated the role of ACE gene I/D polymorphism in relation to the risk of OSF and OL in the aboriginal population of Taiwan, which has a high prevalence of betel quid chewing.

\section{MATERIALS AND METHODS}

\section{Recruitment of study subjects}

Between January 2001 and December 2003, the Taiwan Bureau of National Health Insurance conducted the Taiwan Aboriginal Health Interview and Integrated Health Care Program in rural indigenous people over 30 years old. Using population registries, a total of 826 residents were screened for oral mucosal lesions in a Pai-wan tribe community in Pingtung County. Oral OSF and OL lesions were diagnosed on the basis of past history, oral examination and pathologic confirmation of the lesions according to the World Health Organisation (WHO) criteria (Wahi et al, 1966).

All study subjects lived in the same region at the time of the study and were of Pai-Wan ethnicity without known ancestry from other ethnicities. This study was approved by the Human Research Ethics Committee of our hospital, and informed consent was obtained from each participant. Each subject was interviewed face to face about demographic information, occupation, betel quid chewing, smoking history and alcohol drinking habits, as well as personal and family history of various cancers. The age at which 
the habit was started, average daily consumption quantity and the age at which the habit was stopped were queried in detail for betel quid chewing, cigarette smoking and alcohol drinking. Cumulative exposure to betel quid chewing was derived by multiplying the daily consumption of betel quid chewing (in quid/day) by the duration of betel quid chewing (in years). Valid questionnaires were examined further by a structured questionnaire. Blood pressure, body height and weight were measured and body mass index (BMI) was calculated. Blood was also collected; serum and white blood cells (WBCs) were separated on the day of blood collection and frozen at $-70^{\circ} \mathrm{C}$ until subsequent analysis.

\section{Laboratory analysis}

Genomic DNA was prepared from peripheral blood using standard techniques. For the ACE I/D polymorphism, the primer pairs used and the annealing temperatures were as follows: forward, $5^{\prime}$-CTGGAGACCACTCCCATCCTTTCT- ${ }^{\prime}$; and reverse, $5^{\prime}$-GAT GTGGCCATCACATTCGTCAGAT-3', which amplify the intron 16 region where the I/D fragment is located. Polymerase chain reaction (PCR) amplification products were obtained using $25 \mu \mathrm{l}$ reactions $\left(0.5 \mathrm{pg}\right.$ genomic DNA, $500 \mathrm{pmol}$ of primers, $0.5 \mathrm{mmoll}^{-1}$ each of deoxy-ATP, GTP, CTP, TTP and $1.5 \mathrm{mmoll}^{-1} \mathrm{MgCl}_{2} ; 0.5 \mathrm{U}$ Taq DNA polymerase (Takara Tag ${ }^{\mathrm{TM}}$, Takara Shuzo Co., Ltd, Otsu Shiga, Japan); $50 \mathrm{mmoll}^{-1} \mathrm{KCl} ; 0.001 \%$ gelatin; $10 \mathrm{mmoll}^{-1}$ Tris$\mathrm{HCl}, \mathrm{pH} 8.3$ ) with $4 \mathrm{~min}$ of denaturation at $94^{\circ} \mathrm{C}$, followed by 35 cycles of $15 \mathrm{~s}$ at $94^{\circ} \mathrm{C}, 5 \mathrm{~s}$ at $67^{\circ} \mathrm{C}$ and $30 \mathrm{~s}$ at $74^{\circ} \mathrm{C}$ in a thermal cycler (Gene Amp PCR System 9700, Perkin-Elmer, Foster City, CA, USA). Reaction was terminated at $72^{\circ} \mathrm{C}$ at $2 \mathrm{~min}$. To avoid ID/ DD mistyping of heterozygote as DD homozygote (Shanmugam et al, 1993), all DD genotype samples were confirmed using a pair of primers that produce an amplified product only in the presence of the insertion, which was used to verify the polymorphism: forward, 5'-TGGGACCACAGCGCCCGCCACTAC-3'; and reverse, $5^{\prime}$-TCGCCAGCCCTCCCATGCCCATAA-3' (Lee and Tsai, 2002). The PCR reaction condition was similar to the procedure for I/D detection, except that the annealing temperature was $62^{\circ} \mathrm{C}$. All PCR products were visualised after electrophoresis on a $2 \%$ agarose gel and ethidium bromide staining. Genotyping was performed in a blinded manner.

\section{Statistical analyses}

Data are shown as the mean \pm s.d. All statistical analyses were performed using SAS statistical software (Version 8.2, SAS Institute Inc., Cary, NC, USA). The two-sample $t$-tests or $\chi^{2}$ tests were used to compare means and proportions between the groups of control and oral precancerous lesions (OPL) when appropriate. To determine whether an association existed between $A C E$ genotype and allele frequency with OPL risk, the significance of the difference in the distribution of genotypes and alleles between OPL patients and control subjects was calculated by $\chi^{2}$ statistic or Fisher's exact test and shown by $P$-value. All $P$-values were twosided. A $P$-value $<0.05$ was considered to be statistically significant. Association of ACE genotypes and OPL was analysed by conditional logistic regression of OPL patients $v s$ controls matched by betel quid chewing duration. To control the potential confounding effects, sex, age, BMI, blood pressure, smoking and drinking status were used as independent variables for adjustment. Conditional logistic regression was carried out with the SAS procedure PROC PHREG. Genotypic data entered the regression model in the form of two dummy variables representing the effect of genotype $A C E \mathrm{I} / \mathrm{D}$ and genotype DD $v s$ the reference category II, respectively.

\section{RESULTS}

There were 185 subjects from a total of 826 rural indigenous people who were found on screening to have oral mucosal lesions and signed consent for further pathologic diagnosis. Among these, 111 subjects were confirmed to have OSF or OL; none had oral cancer, while a total of 50 subjects were excluded, 21 because of missing blood collection and 29 with missing information. Finally, a total of 61 persons were included as case subjects, 10 with OSF, 26 with $\mathrm{OL}$ and $25 \mathrm{OL}$ with both lesions related to betel quid chewing. In all, 61 betel quid chewers without any previous or present lesions in the oral cavity matched for betel quid chewing duration and dosage were used as control subjects. Table 1 presents the clinical characteristics of study subjects. The mean age, gender distribution, BMI, blood pressure, amounts of quid consumption, drinking rate and duration, smoking rate and duration were similar in both

Table I Clinical parameters in patients with OPL and control subjects

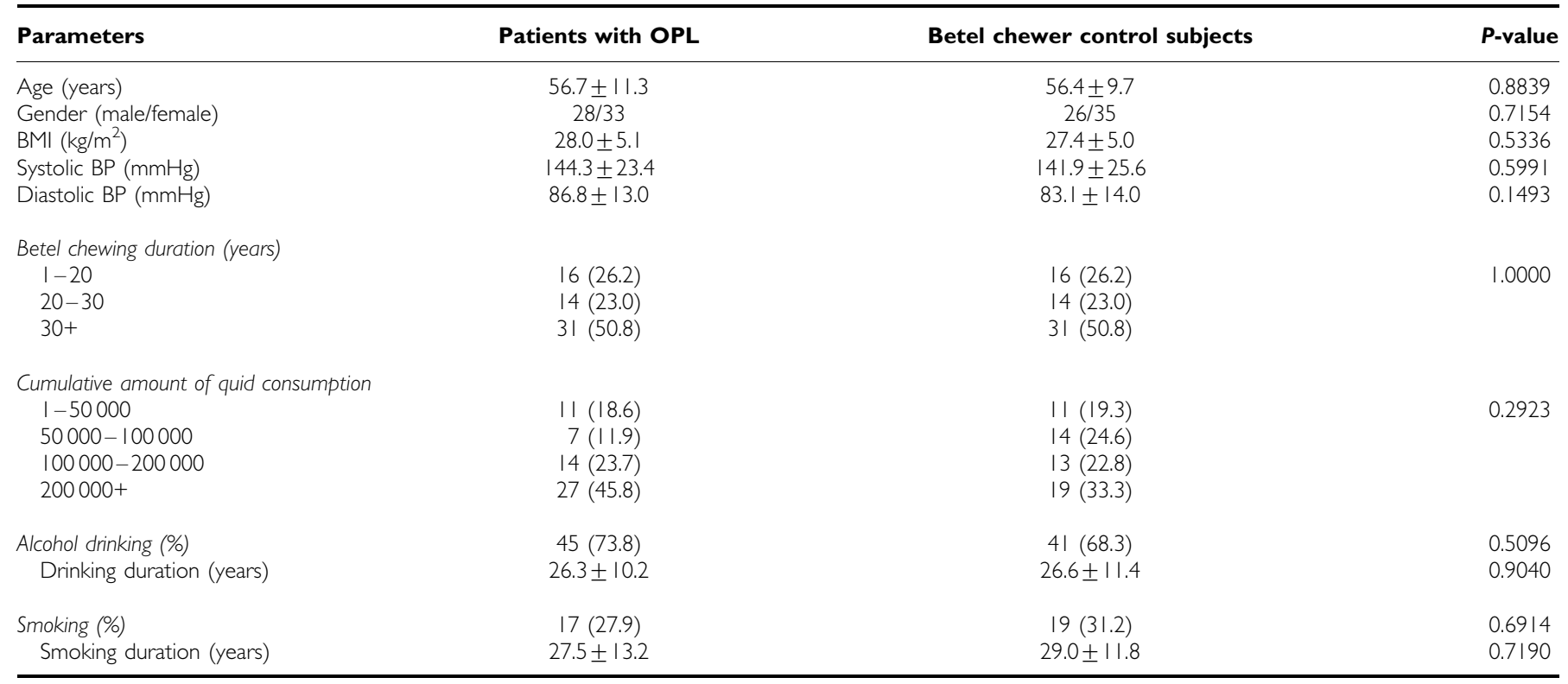

$\mathrm{OPL}=$ oral precancerous lesion; $\mathrm{BMI}=$ body mass index; $\mathrm{BP}=$ blood pressure. Data are expressed as mean \pm s.d.; comparisons performed by unpaired $t$-test or $\chi^{2}$ test when appropriate. 
Table 2 Comparison of ACE genotypes in patients studied

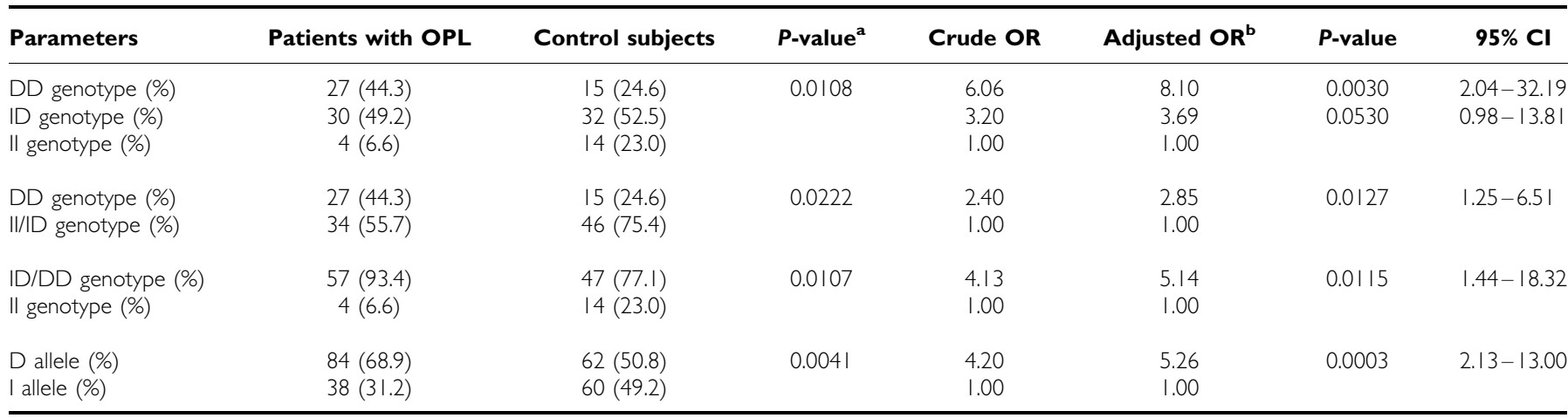

$\mathrm{ACE}=$ angiotensin-converting enzyme; $\mathrm{OPL}=$ oral precancerous lesion; $\mathrm{OR}=$ odds ratio; $\mathrm{Cl}=$ confidence intervals. ${ }^{\mathrm{a}} \mathrm{Comparisons} \mathrm{performed} \mathrm{by} \chi^{2}$ tests. ${ }^{\mathrm{b}} \mathrm{Adjusted}$ by sex, age, body mass index, systolic blood pressure, smoking status and drinking status by conditional logistic regression analysis.

Table 3 Comparison of ACE I/D genotypes in patients studied grouped by smoking status

\begin{tabular}{|c|c|c|c|c|c|c|c|}
\hline Parameters & Patients with OPL & Control subjects & $P$-value ${ }^{a}$ & Crude OR & Adjusted $O R^{b}$ & $P$-value & $95 \% \mathrm{Cl}$ \\
\hline \multicolumn{8}{|l|}{ Smoker } \\
\hline DD genotype (\%) & $6(35.3)$ & $5(26.3)$ & 0.8148 & 1.50 & 2.57 & 0.4932 & $0.17-38.03$ \\
\hline II genotype (\%) & $2(11.8)$ & $2(10.5)$ & & 1.00 & 1.00 & & \\
\hline DD genotype (\%) & $6(35.3)$ & $5(26.3)$ & 0.5593 & 1.39 & 1.97 & 0.3955 & $0.41-9.45$ \\
\hline I//ID genotype (\%) & II (64.7) & $14(73.7)$ & & 1.00 & 1.00 & & \\
\hline ID/DD genotype (\%) & $15(88.2)$ & $17(89.5)$ & 0.9060 & 1.28 & 1.97 & 0.6080 & $0.15-26.24$ \\
\hline I allele (\%) & $13(38.2)$ & $16(42.1)$ & & 1.00 & 1.00 & & \\
\hline \multicolumn{8}{|l|}{ Nonsmoker } \\
\hline DD genotype (\%) & $21(47.7)$ & $10(23.8)$ & 0.0040 & 11.75 & 14.62 & 0.0031 & $2.47-86.44$ \\
\hline ID genotype (\%) & $21(47.7)$ & $20(47.6)$ & & 6.18 & 6.97 & 0.0282 & $1.23-39.46$ \\
\hline II genotype (\%) & $2(4.6)$ & $12(28.6)$ & & 1.00 & 1.00 & & \\
\hline DD genotype (\%) & $21(47.7)$ & $10(23.8)$ & 0.0209 & 2.80 & 3.15 & 0.0225 & $1.18-8.42$ \\
\hline
\end{tabular}

$A C E \mathrm{I} / \mathrm{D}=$ angiotensin-converting enzyme insertion/deletion; $\mathrm{OPL}=$ oral precancerous lesion; $\mathrm{OR}=$ odds ratio; $\mathrm{Cl}=$ confidence intervals. ${ }^{\mathrm{a}} \mathrm{Comparisons}$ performed by Fisher's exact test. ${ }^{b}$ Adjusted by sex, age, body mass index, systolic blood pressure, and drinking status by conditional logistic regression analysis.

groups. The proportions of betel quid chewing duration and cumulative betel quid consumption amount were also similar between the study groups.

The $A C E$ gene I/D genotype distributions and allele frequencies of the study groups are presented in Table 2. The genotype distributions of this polymorphism were in Hardy-Weinberg equilibrium both in the case and control groups. The distribution of $A C E$ genotypes in OPL patients was significantly different $(P=0.0108)$ from that of controls. Patients with OPL had a higher distribution of DD genotype or D allele frequency, indicating the existence of a relationship between $A C E$ gene polymorphism and OPL risk. The association between $A C E \mathrm{DD}$ and ID genotypes and risk of OPL still exist even after adjusting for age, gender, BMI, systolic blood pressure, smoking and drinking status by conditional logistic regression analysis (DD $v s$ II: adjusted odds ratio $(\mathrm{OR})=8.10, \quad 95 \% \quad$ confidence interval $(\mathrm{CI})=2.04-32.19$, $P=0.0030$; ID $v s$ II: adjusted $\mathrm{OR}=3.69,95 \% \mathrm{CI}=0.98-13.81$, $P=0.0530$ ). When analysis was performed comparing the risk of DD genotype $v s$ II/ID genotype or ID/DD genotype $v s$ II genotype and $\mathrm{D}$ allele $v s$ I allele, DD genotype or $\mathrm{D}$ allele still had a significantly higher risk in the association with OPL (Table 2).

As previous reports have indicated that smoking status acts as a contributing factor for OPL (Cahan et al, 1976), we further subgrouped our study subjects according to their smoking status to examine whether if affects the impact of $A C E \mathrm{I} / \mathrm{D}$ polymorphism with risk for OPL. The ACE gene I/D polymorphism was not statistically different between smoking betel quid chewers with or without OPL (Table 3), while the distribution of $A C E$ genotypes in nonsmoking betel quid chewers with OPL was significantly different from that of those without OPL. Subjects with ACE DD and ID genotypes were significantly associated with the risk of OPL when adjusted for age, gender, BMI, blood pressure and drinking status (DD vs II: adjusted $\mathrm{OR}=14.62,95 \% \mathrm{CI}=2.47-86.44$, $P=0.0031$; ID $v s$ II: adjusted $\mathrm{OR}=6.97,95 \% \mathrm{CI}=1.23-39.46$, $P=0.0282$ ). Further analysis comparing the risk of DD genotype $v s$ II/ID genotype or ID/DD genotype $v s$ II genotype and D allele $v s$ I allele showed that DD genotype or D allele had a significantly higher risk in the association with OPL (Table 3 ). 


\section{DISCUSSION}

Although available epidemiological evidence indicates that the chewing of betel quid is an important risk for the development of OSF and OL (Avon, 2004; Yang et al, 2005), not all chewers develop oral mucosal lesions (Yang et al, 2001). Molecular epidemiologic studies have provided evidence that an individual's susceptibility to OSF and OL is modulated by both genetic and environmental factors. Inherited differences in the effectiveness of the disease may play a crucial role in host susceptibility (Chiu et al, 2002; Topcu et al, 2002).

Our previous studies confirmed that betel quid chewing acts as a major risk factor for OPL (Yang et al, 2001, 2005), while the present study further indicates that genetic factors exist in the vulnerability of betel quid chewing-related OPL. The additive used for betel quid chewing in Taiwan is quite different from that of India or Western populations. The betel quid in Taiwan does not contain any tobacco (Yang et al, 2005), while tobacco is usually added to betel quid chewed by Southeast Asians (Nandakumar et al, 1990; Sankaranarayanan et al, 1990). The present study shows that $A C E$ gene I/D polymorphism is significantly associated with betel quid chewing-related OPL both in nonadjusted and adjusted models. To the best of our knowledge, this is the first report showing that $A C E$ gene I/D polymorphism is associated with the risk of OPL in subjects who chew betel quid. Our results support the evidence that genetic factors may interact with environmental factors to contribute to the pathogenesis of OPL (Sikdar et al, 2004; Tsai et al, 2004).

Studies have suggested that molecular mimicry may explain the association among chronic inflammatory infiltrates, human leucocyte antigen and autoimmune disease with the pathogenesis of OSF and OL (Canniff et al, 1985; Tsai et al, 2004). Many cytokines have been thought to play important roles in the pathogenesis of OSF and OL (Chiu et al, 2001). Angiotensin II, the main peptide of the renin-angiotensin system (RAS), is a renal growth factor, inducing hyperplasia/hypertrophy depending on the cell type. It could also be involved in the fibrotic process of the oral cavity because of its behaviour as a proinflammatory cytokine, participating in various steps of the inflammatory response (Mezzano et al, 2001). Previous reports showed that subjects with DD genotype are associated with significantly higher levels of ACE and Ang II than those with I/I genotype, and individuals with the ID genotype have intermediate levels of these two enzymes.

Various immunologic changes are believed to play a role in the pathogenesis of OSF and OL (Canniff et al, 1985; Mega et al, 2001). The increase in CD4 complement and cells with HLA-DR in OSF tissues suggests that most lymphocytes are activated and that the number of Langerhans cells increases. Haque et al (1997) studied subjects with OSF with immunohistochemical methods and found immunocompetent cells to be present in the lesion, with a high ratio of $\mathrm{CD} 4$ to $\mathrm{CD} 8$ cells. Therefore, they suggested an ongoing cellular immune response leading to a possible imbalance of immunoregulation with eventual local alterations in tissue architecture. Angiotensin II is also known to play an important role in immune cells (Nakagawa et al, 2000), Papadopoulos et al (2000) showed that the ACE D allele in its homozygous form might confer susceptibility for autoimmune manifestations in sarcoidosis. Sato et al (1998) also revealed that the ACE genotype could be associated with the disease activity of SLE. Thus, subjects with the $A C E$ gene D allele may, through the increased effect of Ang II, on cytokine activation, chronic inflammation and immune modulation, contribute to the increased risk of OSF and OL.

Cigarette smokers are more likely to develop many forms of disease than nonsmokers, including oral diseases. However, our study did not show an increased risk of precancerous lesions in smoking betel chewers with $A C E$ gene D allele. Recently, Wang and co-workers reported that GSTM1 deficiency is associated with the risk of vascular diseases, while they did not observe any interaction between the status of cigarette smoking and GSTM1 deficiency in relation to coronary arterial disease severity (Wang and Wang, 2005). Similar findings were reported by Kelada et al (2000) that also did not find an interactive effect between smoking and GSTM1 non-null genotype of prostate cancer. Our results show that $A C E$ gene I/D polymorphism and cigarette smoking status have no synergistic or additive effect in relation to the risk of OPL. This fact may suggest that smoking and genetic factors may be differently involved in the development of OPL disease.

In summary, our study shows an association of the ACE gene I/D polymorphism with OSF and OL in a Taiwan aboriginal population. These results imply that susceptibility to OSF and OL could involve genetic mechanisms modified by betel quid exposure. The present study also suggests that the RAS may be involved in the pathophysiology of inflammatory reaction and immunologic derangement in OSF and OL. Further work is required to confirm these findings in populations of different races and these preliminary exploratory results should be confirmed in a larger study.

\section{ACKNOWLEDGEMENTS}

We are grateful to the staff of the Aboriginal Health Promotion Center and the health bureaus in aboriginal communities for their assistance in measurements and other organisational aspects of this study. This work was supported by grants from the National Science Council (92-2314-B-037-074) and the Department of Health of Taiwan (DOH92-HP-1111).

\section{REFERENCES}

Arkwright PD, Pravica V, Geraghty PJ, Super M, Webb AK, Schwarz M, Hutchinson IV (2003) End-organ dysfunction in cystic fibrosis: association with angiotensin I converting enzyme and cytokine gene polymorphisms. Am J Respir Crit Care Med 167: 384-389

Avon SL (2004) Oral mucosal lesions associated with use of quid. J Can Dent Assoc 70: $244-248$

Aziz SR (1997) Oral submucous fibrosis: an unusual disease. $J$ N J Dent Assoc 68: 17-19

Cahan WG, Castro EB, Rosen PP, Strong EW (1976) Separate primary carcinomas of the esophagus and head and neck region in the same patient. Cancer 37: 85-89

Canniff JP, Batchelor JR, Dodi IA, Harvey W (1985) HLA-typing in oral submucous fibrosis. Tissue Antigens 26: $138-142$

Chiu CJ, Chang ML, Chiang CP, Hahn LJ, Hsieh LL, Chen CJ (2002) Interaction of collagen-related genes and susceptibility to betel quid-

induced oral submucous fibrosis. Cancer Epidemiol Biomarkers Prev 11: $646-653$

Chiu CJ, Chiang CP, Chang ML, Chen HM, Hahn LJ, Hsieh LL, Kuo YS, Chen CJ (2001) Association between genetic polymorphism of tumor necrosis factor-alpha and risk of oral submucous fibrosis, a precancerous condition of oral cancer. J Dent Res 80: 2055-2059

Cox SC, Walker DM (1996) Oral submucous fibrosis. A review. Aust Dent $J$ 41: $294-299$

Haque MF, Harris M, Meghji S, Speight PM (1997) An immunohistochemical study of oral submucous fibrosis. J Oral Pathol Med 26: $75-82$

Kao SY, Wu CH, Lin SC, Yap SK, Chang CS, Wong YK, Chi LY, Liu TY (2002) Genetic polymorphism of cytochrome P4501A1 and susceptibility to oral squamous cell carcinoma and oral precancer lesions associated with smoking/betel use. J Oral Pathol Med 31: 505-511 
Kelada SN, Kardia SL, Walker AH, Wein AJ, Malkowicz SB, Rebbeck TR (2000) The glutathione $S$-transferase-mu and -theta genotypes in the etiology of prostate cancer: genotype-environment interactions with smoking. Cancer Epidemiol Biomarkers Prev 9: 1329-1334

Lee CH, Ko YC, Huang HL, Chao YY, Tsai CC, Shieh TY, Lin LM (2003) The precancer risk of betel quid chewing, tobacco use and alcohol consumption in oral leukoplakia and oral submucous fibrosis in southern Taiwan. Br J Cancer 88: 366-372

Lee YJ, Tsai JC (2002) ACE gene insertion/deletion polymorphism associated with 1998 World Health Organization definition of metabolic syndrome in Chinese type 2 diabetic patients. Diabetes Care 25: $1002-$ 1008

Liu CJ, Lee YJ, Chang KW, Shih YN, Liu HF, Dang CW (2004) Polymorphism of the MICA gene and risk for oral submucous fibrosis. J Oral Pathol Med 33: 1-6

Luther Y, Bantis C, Ivens K, Fehsel K, Kolb-Bachhofen V, Heering P (2003) Effects of the genetic polymorphisms of the renin-angiotensin system on focal segmental glomerulosclerosis. Kidney Blood Pressure Res 26: $333-337$

Mega H, Jiang WW, Takagi M (2001) Immunohistochemical study of oral lichen planus associated with hepatitis $\mathrm{C}$ virus infection, oral lichenoid contact sensitivity reaction and idiopathic oral lichen planus. Oral Dis 7: $296-305$

Mezzano SA, Ruiz-Ortega M, Egido J (2001) Angiotensin II and renal fibrosis. Hypertension 38: 635-638

Morrison CD, Papp AC, Hejmanowski AQ, Addis VM, Prior TW (2001) Increased D allele frequency of the angiotensin-converting enzyme gene in pulmonary fibrosis. Hum Pathol 32: $521-528$

Nair UJ, Nair J, Mathew B, Bartsch H (1999) Glutathione S-transferase M1 and $\mathrm{T} 1$ null genotypes as risk factors for oral leukoplakia in ethnic Indian betel quid/tobacco chewers. Carcinogenesis 20: $743-748$

Nakagawa Y, Takeshita T, Berzofsky JA, Takahashi H (2000) Analysis of the mechanism for extracellular processing in the presentation of human immunodeficiency virus-1 envelope protein-derived peptide to epitopespecific cytotoxic T lymphocytes. Immunology 101: 76-82

Nandakumar A, Thimmasetty KT, Sreeramareddy NM, Venugopal TC, Rajanna, Vinutha AT, Srinivas, Bhargava MK (1990) A population-based case-control investigation on cancers of the oral cavity in Bangalore, India. $\mathrm{Br}$ J Cancer 62: 847-851

Noveral JP, Mueller SN, Levine EM (1987) Release of angiotensin Iconverting enzyme by endothelial cells in vitro. J Cell Physiol 131: $1-5$

Papadopoulos KI, Melander O, Orho-Melander M, Groop LC, Carlsson M, Hallengren B (2000) Angiotensin converting enzyme (ACE) gene polymorphism in sarcoidosis in relation to associated autoimmune diseases. I Intern Med 247: $71-77$

Petrov V, Fagard R, Lijnen P (2000) Effect of protease inhibitors on angiotensin-converting enzyme activity in human T-lymphocytes. Am J Hypertens 13: $535-539$

Sankaranarayanan R, Duffy SW, Padmakumary G, Day NE, Krishan Nair M (1990) Risk factors for cancer of the buccal and labial mucosa in Kerala, southern India. J Epidemiol Community Health 44: 286-292

Sato H, Akai Y, Iwano M, Kurumatani N, Kurioka H, Kubo A, Yamaguchi T, Fujimoto T, Dohi K (1998) Association of an insertion polymorphism of angiotensin-converting enzyme gene with the activity of systemic lupus erythematosus. Lupus 7: 530-534

Shanmugam V, Sell KW, Saha BK (1993) Mistyping ACE heterozygotes. PCR Methods Appl 3: 120-121

Shin YN, Liu CJ, Chang KW, Lee YJ, Liu HF (2004) Association of CTLA-4 gene polymorphism with oral submucous fibrosis in Taiwan. J Oral Pathol Med 33: 200-203

Sikdar N, Paul RR, Roy B (2004) Glutathione S-transferase M3 (A/A) genotype as a risk factor for oral cancer and leukoplakia among Indian tobacco smokers. Int J Cancer 109: 95-101

Smallridge RC, Gamblin GT, Eil C (1986) Angiotensin-converting enzyme: characteristics in human skin fibroblasts. Metabolism 35: 899-904

Topcu Z, Chiba I, Fujieda M, Shibata T, Ariyoshi N, Yamazaki H, Sevgican F, Muthumala M, Kobayashi H, Kamataki T (2002) CYP2A6 gene deletion reduces oral cancer risk in betel quid chewers in Sri Lanka. Carcinogenesis 23: $595-598$

Tsai CH, Yang SF, Chen YJ, Chu SC, Hsieh YS, Chang YC (2004) Regulation of interleukin-6 expression by arecoline in human buccal mucosal fibroblasts is related to intracellular glutathione levels. Oral Dis 10: 360 364

Wahi PN, Kapur VL, Luthra UK, Srivastava MC (1966) Submucous fibrosis of the oral cavity. 2. Studies on epidemiology. Bull World Health Organ 35: $793-799$

Wang XL, Wang J (2005) Smoking-gene interaction and disease development: relevance to pancreatic cancer and atherosclerosis. World J Surg 29: $344-353$

Yang YH, Lee HY, Tung S, Shieh TY (2001) Epidemiological survey of oral submucous fibrosis and leukoplakia in aborigines of Taiwan. J Oral Pathol Med 30: 213-219

Yang YH, Lien YC, Ho PS, Chen CH, Chang JSF, Cheng TC, Shieh TY (2005) The effects of chewing areca/betel quid with and without cigarette smoking on oral submucous fibrosis and oral mucosal lesions. Oral Dis 11: $88-94$ 